\title{
The impact of patient delirium in the intensive care unit: patterns of anxiety symptoms in family caregivers
}

Therese G. Poulin ${ }^{1}$, Karla D. Krewulak², Brianna K. Rosgen ${ }^{3}$, Henry T. Stelfox ${ }^{4}$, Kirsten M. Fiest ${ }^{{ }^{*}}$ and Stephana J. Moss ${ }^{6}$

\begin{abstract}
Background: The purpose of this study was to examine the association of patient delirium in the intensive care unit (ICU) with patterns of anxiety symptoms in family caregivers when delirium was determined by clinical assessment and family-administered delirium detection.

Methods: In this cross-sectional study, consecutive adult patients anticipated to remain in the ICU for longer than $24 \mathrm{~h}$ were eligible for participation given at least one present family caregiver (e.g., spouse, friend) provided informed consent (to be enrolled as a dyad) and were eligible for delirium detection (i.e., Richmond AgitationSedation Scale score $\geq-3$ ). Generalized Anxiety Disorder-7 (GAD-7) was used to assess self-reported symptoms of anxiety. Clinical assessment (Confusion Assessment Method for ICU, CAM-ICU) and family-administered delirium detection (Sour Seven) were completed once daily for up to five days.

Results: We included 147 family caregivers; the mean age was 54.3 years (standard deviation [SD] 14.3 years) and $74 \%(n=129)$ were female. Fifty (34\% [95\% confidence interval [CI] 26.4-42.2]) caregivers experienced clinically significant symptoms of anxiety (median GAD-7 score 16.0 [interquartile range 6]). The most prevalent symptoms of anxiety were "Feeling nervous, anxious or on edge" (96.0\% [95\%Cl 85.2-99.0]); "Not being able to stop or control worrying" (88.0\% [95\%Cl 75.6-94.5]; "Worrying too much about different things" and "Feeling afraid as if something awful might happen" (84.0\% [95\%Cl 71.0-91.8], for both). Family caregivers of critically ill adults with delirium were significantly more likely to report "Worrying too much about different things" more than half of the time (CAM-ICU, Odds Ratio [OR] 2.27 [95\%Cl 1.04-4.91]; Sour Seven, OR 2.28 [95\%Cl 1.00-5.23]).

Conclusions: Family caregivers of critically ill adults with delirium frequently experience clinically significant anxiety and are significantly more likely to report frequently worrying too much about different things. Future work is needed to develop mental health interventions for the diversity of anxiety symptoms experienced by family members of critically ill patients.
\end{abstract}

Trial registration: This study is registered on ClinicalTrials.gov (https://clinicaltrials.gov/ct2/show/NCT03379129).

Keywords: Critical care, Delirium, Family, Anxiety, Intensive care unit, Engagement

\footnotetext{
* Correspondence: kmfiest@ucalgary.ca

${ }^{5}$ Departments of Critical Care Medicine, Community Health Sciences \&

Psychiatry, Cumming School of Medicine, University of Calgary, Calgary, AB

T2N 1N4, Canada

Full list of author information is available at the end of the article
}

(C) The Author(s). 2021 Open Access This article is licensed under a Creative Commons Attribution 4.0 International License, which permits use, sharing, adaptation, distribution and reproduction in any medium or format, as long as you give appropriate credit to the original author(s) and the source, provide a link to the Creative Commons licence, and indicate if changes were made. The images or other third party material in this article are included in the article's Creative Commons licence, unless indicated otherwise in a credit line to the material. If material is not included in the article's Creative Commons licence and your intended use is not permitted by statutory regulation or exceeds the permitted use, you will need to obtain permission directly from the copyright holder. To view a copy of this licence, visit http://creativecommons.org/licenses/by/4.0/ The Creative Commons Public Domain Dedication waiver (http://creativecommons.org/publicdomain/zero/1.0/) applies to the data made available in this article, unless otherwise stated in a credit line to the data. 


\section{Background}

Critical illness is defined as an illness that is life-altering or life-threatening [1]. Critically ill patients are admitted to the intensive care unit (ICU) when they are fighting for their lives as these patients have complicated medical problems that require urgent treatment with lifesustaining technologies [2]. Critically ill patients in the ICU are among the sickest patients in in the healthcare system and caring for them is costly; ICU care accounts for $0.5-1 \%$ of the GDP [3].

Delirium occurs frequently among ICU patients [4], a serious and distressing neuropsychiatric syndrome with acute onset that fluctuates throughout the day [5]. Despite high prevalence of delirium in the ICU (estimates reported up to $80 \%$ in mechanically ventilated patients) $[6,7]$, delirium is often underdiagnosed and undertreated [8]. Screening vulnerable ICU patients for delirium is important for timely implementation of prevention and management measures [9].

Apart from the patient, family, or informal caregivers (i.e., relatives, friends) of critically ill patients are the only constant in the care journey. Family caregivers are essential members of the ICU team who often act as surrogate decision makers and important emotional supports during and after critical illness [10]. Family caregivers are not passive bystanders-they may recognize subtle changes in a patient first, provide a locus of familiarity for the patient, are important in improving processes of care associated with ICU transitions (to the hospital ward or to the community), and often act as advocates for the patient regarding treatment decisions [11].

Patients with delirium are often unable to communicate [12], which results in high levels of distress [13] and negative emotions in family caregivers of critical ill patients with delirium [14]. Highly distressed family caregivers may experience a breakdown in their relationship with the patient and may experience feelings of helplessness in relation to how to support their loved one [15]. A systematic review by Finucane and colleagues that consolidated experiences of family caregivers of terminally ill patients with delirium found that high levels of distress are experiences by caregivers of patients with delirium; reducing family caregiver distress and anxiety should be an important goal [16]. To inform future interventions the objective of this study was to examine the association of patient delirium in the ICU with patterns of anxiety symptoms in family caregivers when delirium was determined by clinical assessment and family-administered delirium detection [17, 18]. We hypothesized that family caregivers of critically ill patients with delirium would exhibit clinically significant patterns of anxiety symptoms [19-21].

\section{Methods}

\section{Participants}

Between December 2017 and March 2019, 910 adult patients were admitted to the FMC ICU (Fig. 1). One hundred ninety-six dyads were approached for consent (out of 881 screened), of which 158 dyads were enrolled in the study; at least $24 \mathrm{~h}$ of data was obtained for $147 / 158$ dyads (93\%) [18] to achieve $95 \%$ sensitivity and $75 \%$ specificity, with a $10 \%$ margin of error and $80 \%$ power, estimating that $60 \%$ of critically ill patients would develop delirium [22]. Patient-family dyads were recruited from the Foothills Medical Centre (FMC, Calgary, Canada); a single-centre large academic hospital in a single-payer healthcare system (28 closed beds). Eligibility for participation (Table 1) was assessed daily by a trained research assistant granted approval from the bedside nurse. Consecutive eligible patients with at least one present family caregiver who provided informed consent were enrolled in the study as a patient-family dyad.

\section{Procedure}

Data were collected on eligible patients in the ICU up to a maximum of five days. Patient and family caregiver demographics were collected at first assessment. Patient clinical characteristics (e.g., Acute Physiology and Chronic Health Evaluation-II [APACHE-II]) were obtained from a beside clinical information database [eCritical] previously validated for research purposes [23]. Approval from the Conjoint Health Research Ethics Board at the University of Calgary was granted (REB 162060).

\section{Measures \\ Clinical delirium detection}

Clinical assessment of patient delirium was conducted twice daily by a trained research assistant using the Confusion Assessment Method-ICU (CAM-ICU), a fouritem dichotomous (i.e., delirium present, delirium absent) ICU delirium detection tool with published sensitivity (range: $69-82 \%$ ) and specificity (range: $78-87 \%$ ) in this sample [18].

\section{Family-administered delirium detection}

Family assessment of patient delirium (i.e., Sour Seven) was conducted once daily up to a maximum of five days. Family caregivers were blinded to results from clinical delirium assessments (and vice versa). In the present study, family caregivers assessed patient delirium using the Sour Seven, a family assessment of patient delirium symptoms related to altered awareness, disordered thinking, and reduced attention [24]. The Sour Seven was scored out of 18 with a cutpoint of $\geq 4$ (i.e., probable delirium); in this cohort scores $\geq 4$ have $73 \%$ sensitivity 


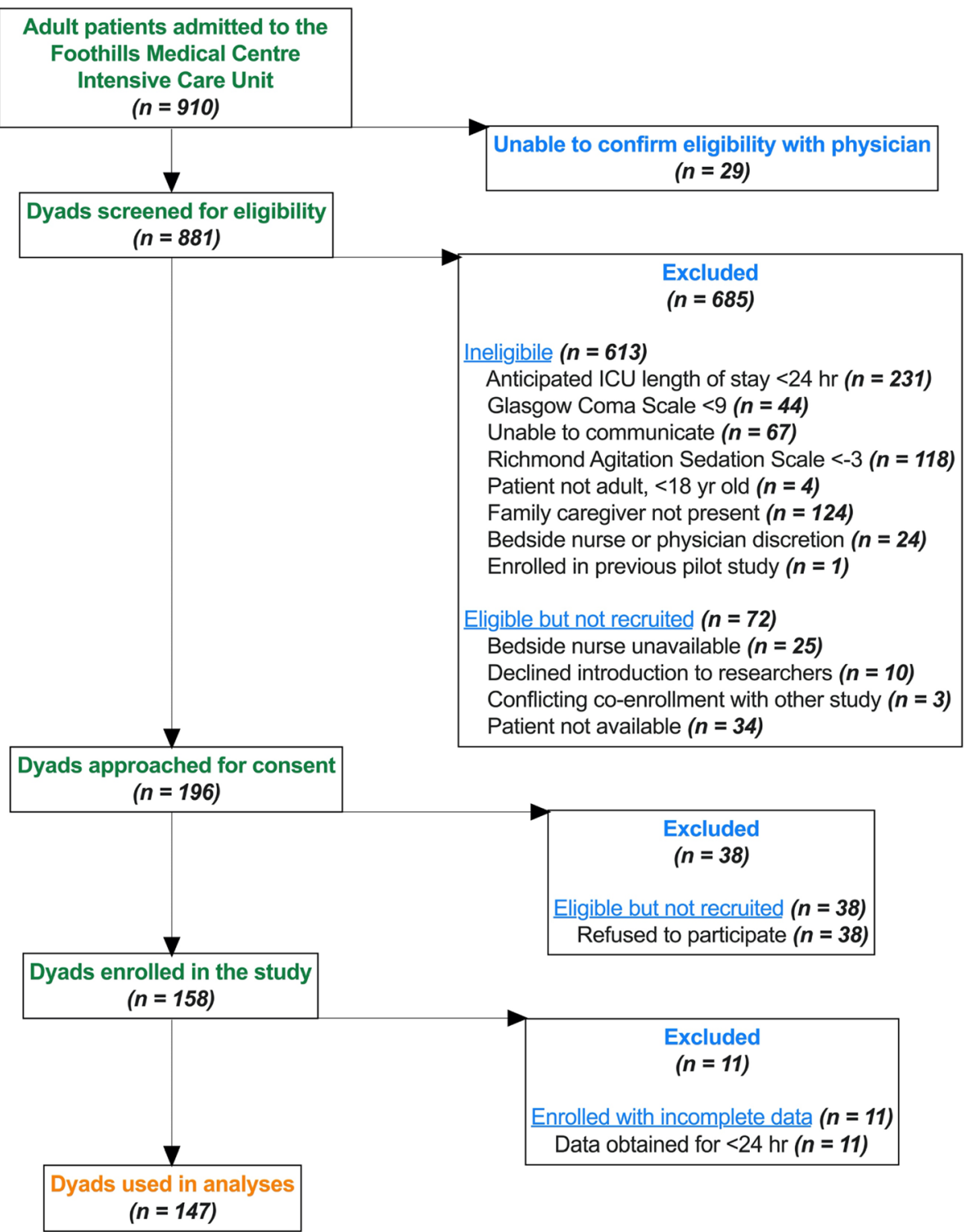

Fig. 1 Study Flow Diagram

Table 1 Study Eligibility Criteria

\begin{tabular}{l}
\hline Inclusion criteria \\
\hline Age 18 years or older \\
Family member present \\
Richmond Agitation-Sedation Scale score $\geq 3$ (eligible for delirium \\
detection) \\
Exclusion criteria \\
Patient or family did not provide informed consent \\
Unable to community with research staff (e.g., hearing impairment, not \\
fluent in English) \\
Anticipated to have an ICU length of stay $<24 \mathrm{~h}$ \\
New primary neurologic injury (e.g., severe traumatic brain injury) \\
Glasgow Coma Scale score $<9$
\end{tabular}

and $69 \%$ specificity [18]. This tool is administered easily without direct patient query [24].

\section{Generalized anxiety disorder}

Symptoms of generalized anxiety disorder among family caregivers were assessed with the Generalized Anxiety Disorder-7 (GAD-7) scale [25]. The GAD-7 is a selfreport assessment of 7 -items which measure GAD symptoms within the past two weeks using a four-point Likert-type scale $(0=$ "Not at all" to $3=$ "Nearly every day" [range:0-21]). A cutpoint score of 10 (of 21) was used to indicate clinically significant GAD [26] with $89 \%$ 
sensitivity, $82 \%$ specificity [27]. In this study GAD symptom severity subgroups were scored as $0-5=$ none; $6-$ $19=$ mild $; 1-15=$ moderate; and $16-21=$ severe [25].

\section{Study design}

This cross-sectional study is reported according to Strengthening the Reporting of Observational Studies in Epidemiology (STROBE) guidelines (Supplemental Table 1).

\section{Data analysis}

Data are presented as numbers/percentage, mean or median, and compared statistically by $t$-tests or tests of proportions as appropriate. Prevalence estimates are reported with accompanying 95\% confidence intervals (CIs). For the Sour Seven and GAD-7, the single most severe score or the first score (if all scores equally severe) were used in statistical analyses for each patientfamily dyad [28]. No imputation techniques were used to handle missing data. Separate ordinal logistic regression analyses were computed for all seven items in the GAD-7 to determine the odds of scoring $\geq 2$ (i.e., selfreported symptoms experienced more than half of the days) on each item based on patient delirium status regarding individual delirium detection assessment tools. Models were adjusted for family member age (dichotomized at 65 years $[29,30])$, family member sex, family member education (high school or less, university/college), and patient APACHE-II score. Statistical analyses were conducted in STATA ICV.16 (StataCorp. College Station, TX: StataCorp LLC) and all $p$-values correspond to 2-tailed tests; $p<0.05$ denotes significance.

\section{Results}

Mean age of patients was 56.1 years (standard deviation [SD] 16.2) and 58 (39.5\%) patients were female (Table 2). Nearly half of patients $(n=67,45.6 \%)$ were admitted with a medical diagnosis and a median APACHE-II score of 20 (interquartile range [IQR], 12). As detected by the family-administered Sour Seven, 64.6\% (95\%CI 56.5-72.0) of critically ill patients experienced delirium at least once during their ICU stay, which was significantly higher compared to CAM-ICU clinical assessments $(35.5$, 95\%CI 28.0-43.5; $p<0.001)$ (Supplemental Table 2).

\section{Prevalence of anxiety symptoms in family caregivers of critically ill patients}

Among $34.0 \%(n=50 / 147)$ of family caregivers with clinically significant anxiety symptoms [GAD-7 $\geq 10$ / 21] (median GAD-7 score 16.0 [IQR 6]), mean age was 54.5 years (SD 13.3), of which $90 \%(n=45)$ were female with at least some university or college education $(n=33,66.0 \%)$.
When anxiety symptoms were stratified by level of severity, we found that most family caregivers frequently had none $(n=66,44.9 \%)$ or mild $(n=34,23.1 \%)$ symptoms of anxiety among which the majority were female (none, 45/66, 68.2\%; mild, 21/34, 61.8\%) and with higher education (none, 43/66, 65.2\%; mild, 22/34, 64.7\%). Many family caregivers self-reported severe $(n=29$, $19.7 \%)$ symptoms of anxiety. Family caregivers with severe symptoms of anxiety were mostly female (96.7\%) and younger (mean age 49.7 years [SD 12.5]) compared to family caregivers in other anxiety symptom severity subgroups. Overall, relatively fewer family caregivers ( $n=18,12.2 \%$ ) reported moderate severity symptoms.

Most prevalent symptoms of anxiety experienced by family caregivers of critically ill patients more than half of the days (i.e., item score 2 or greater) were: Item 1, "Feeling nervous, anxious or on edge" and Item 2, "Not being able to stop or control worrying." Item-level prevalence estimates for all included family caregivers are shown in Supplemental Table 3.

\section{Prevalence of anxiety symptoms in family caregivers of critically ill delirium patients}

Estimated prevalence of self-reported clinically significant symptoms of anxiety among family caregivers of critically ill patients with delirium assessed by the CAMICU was $40.4 \%$ (95\%CI 27.9-54.2) (Table 3). When patient delirium was detected by the family-administered Sour Seven compared to the clinical CAM-ICU tool, prevalence of clinically significant symptoms of anxiety among family caregivers was not significantly different (35.8, 95\%CI 36.7-46.0; $p=0.58)$. Most prevalent symptoms of anxiety experienced by family caregivers of critically ill patients with delirium more than half of the days were: Item 1, "Feeling nervous, anxious or on edge" (Sour Seven, 44.2\% [95\%CI 34.5-54.4]); Item 2, "Not being able to stop or control worrying" (CAM-ICU, $44.2 \%$ [95\%CI 31.4-57.9]; Sour Seven, 41.4\% [95\%CI 31.651.3]); Item 3, "Worrying too much about different things" (CAM-ICU, 44.2\% [95\%CI 31.4-57.9]); and Item 7, "Feeling afraid as if something awful might happen" (CAM-ICU, 46.2\% [95\%CI 33.1-59.8]; Sour Seven, 41.1\% [95\%CI 31.6-51.3]).

\section{Associations of family caregiver anxiety symptoms}

Figure 2 illustrates self-reported anxiety symptoms in family members of patients with and without delirium by patient delirium detection tool; results are presented in Table 4, with values adjusted for family age, family sex, family education and dichotomized (at median) patient APACHE-II score. Family caregivers of critically ill patients with delirium scored significantly higher than family caregivers of critically ill patients without delirium on item 3 regarding "Worrying too much about different 
Table 2 Demographic and Clinical Characteristics of Included Patients and Family Caregivers

\begin{tabular}{|c|c|c|c|c|c|c|}
\hline \multirow[t]{2}{*}{ Characteristic } & \multirow[t]{2}{*}{ Patient } & \multicolumn{5}{|l|}{ Family Caregiver $^{\mathrm{e}, \mathrm{f}}$} \\
\hline & & $\begin{array}{l}\text { Clinically Significant } \\
\text { Anxiety }^{9}\end{array}$ & $\begin{array}{l}\text { No } \\
\text { Anxiety }\end{array}$ & $\begin{array}{l}\text { Mild } \\
\text { Anxiety }\end{array}$ & $\begin{array}{l}\text { Moderate } \\
\text { Anxiety }^{\mathrm{h}}\end{array}$ & $\begin{array}{l}\text { Severe } \\
\text { Anxiety }^{h}\end{array}$ \\
\hline$\overline{N(\%)}$ & $\begin{array}{l}147 \\
(100)\end{array}$ & $50(34.0)$ & $66(44.9)$ & $34(23.1)$ & $18(12.2)$ & $29(19.7)$ \\
\hline Age, yr, mean $(S D)^{a}$ & $\begin{array}{l}56.1 \\
(16.2)\end{array}$ & $54.5(13.3)$ & $55.6(14.0)$ & $51.6(14.7)$ & $61.6(11.0)$ & $49.7(12.5)$ \\
\hline Sex, female, $n(\%)$ & $\begin{array}{l}58 \\
(39.5)\end{array}$ & $45(90.0)$ & $45(68.2)$ & $21(61.8)$ & $14(77.8)$ & $28(96.7)$ \\
\hline \multicolumn{7}{|l|}{ Education, $n(\%)^{\mathrm{b}}$} \\
\hline High school or less & $\begin{array}{l}72 \\
(49.7)\end{array}$ & $17(34.0)$ & $23(34.9)$ & $12(35.3)$ & $8(44.4)$ & $8(27.6)$ \\
\hline Some university/college or greater & $\begin{array}{l}73 \\
(50.3)\end{array}$ & $33(66.0)$ & $43(65.2)$ & $22(64.7)$ & $10(55.6)$ & $21(72.4)$ \\
\hline \multicolumn{7}{|l|}{ Patient admitting diagnosis category, $n$ (\%) } \\
\hline Medical & $\begin{array}{l}67 \\
(45.6)\end{array}$ & $23(46.0)$ & $32(48.5)$ & $14(41.2)$ & $11(61.1)$ & $11(37.9)$ \\
\hline Neurologic & $\begin{array}{l}31 \\
(21.1)\end{array}$ & $12(24.0)$ & $12(18.2)$ & $9(26.5)$ & $3(16.7)$ & $7(24.1)$ \\
\hline Trauma & $\begin{array}{l}27 \\
(18.4)\end{array}$ & $9(18.0)$ & $11(16.7)$ & $6(17.5)$ & $3(15.6)$ & $6(20.7)$ \\
\hline Surgical & $\begin{array}{l}22 \\
(18.4)\end{array}$ & $6(12.0)$ & $11(16.7)$ & $5(14.7)$ & $1(5.6)$ & $5(17.2)$ \\
\hline $\begin{array}{l}\text { Acute Physiology and Chronic Health Evaluation II } \\
\text { score, median (IQR) }\end{array}$ & $20(12)$ & $18(10)$ & $21(13)$ & $19(10)$ & $21(10)$ & $17(11)$ \\
\hline Analgo-sedative use, $n(\%)$ & $\begin{array}{l}120 \\
(81.6)\end{array}$ & $42(84.0)$ & $50(75.8)$ & $30(88.2)$ & $13(72.2)$ & $27(93.1)$ \\
\hline \multicolumn{7}{|l|}{ Patient Delirium, $n$ (\%) } \\
\hline CAM-ICU & $\begin{array}{l}52 \\
(35.4)\end{array}$ & $21(40.4)$ & $19(36.5)$ & $14(26.9)$ & $5(9.62)$ & $14(26.9)$ \\
\hline Sour Seven ${ }^{d}$ & $\begin{array}{l}95 \\
(64.6)\end{array}$ & $34(35.8)$ & $36(37.9)$ & $28(29.5)$ & $7(7.37)$ & $24(25.3)$ \\
\hline Generalized Anxiety Disorder-7 score & - & & & & & \\
\hline Median (IQR) & - & $16(6)$ & $3(3)$ & $7(2)$ & $13(3)$ & $19(3)$ \\
\hline
\end{tabular}

$\mathrm{IQR}=$ interquartile range

$\mathrm{SD}=$ standard deviation

GAD-7 = Generalized Anxiety Disorder-7

a One missing family member age

${ }^{\mathrm{b}}$ Two missing patient education and one missing family education

'Scored as present/absent

${ }^{d}$ Sour Seven is scored out of 18; cutpoint of 4

eNone missing family anxiety assessment

${ }^{f}$ Assessed by the Generalized Anxiety Disorder-7

${ }^{9}$ Scores 10 and above indicate clinically significant condition

${ }^{\mathrm{h}} \mathrm{S}$ cored as $0-5=$ none; $6-19=$ mild; $11-15=$ moderate; $16-21=$ severe

Dashes indicate no data to report for that group

things" (CAM-ICU, OR 2.27 [95\%CI 1.04-4.91]; Sour Seven, OR 2.28 [95\%CI 1.00-5.23]).

\section{Discussion}

In this observational study we sought to examine the association of patient delirium in the ICU with patterns of anxiety symptoms in family caregivers when delirium was determined by clinical assessment and family- administered delirium detection. We hypothesized that family caregivers of critically ill patients with delirium would exhibit clinically significant patterns of anxiety symptoms [19-21]. Our study has two main findings. First, family caregivers of critically ill patients with delirium (compared to those without delirium) were more likely to report "Worrying too much about different things" more than half of the time. This may imply that 
Table 3 Anxiety Prevalence for GAD-7 Items by Patient Delirium Detection

\begin{tabular}{|c|c|c|}
\hline GAD-7 Items ${ }^{a}$ & $\begin{array}{l}\text { Clinical Assessment } \\
\text { CAM-ICUc }\end{array}$ & $\begin{array}{l}\text { Family-Administered } \\
\text { Sour Seven }^{d}\end{array}$ \\
\hline Feeling nervous, anxious or on edge & $42.3(29.6-56.1)$ & $44.2(34.5-54.4)$ \\
\hline Not being able to stop or control worrying & $44.2(31.4-57.9)$ & $41.4(31.6-51.3)$ \\
\hline Worrying too much about different things & $44.2(31.4-57.9)$ & $36.8(27.7-47.0)$ \\
\hline Trouble relaxing & $38.5(26.2-52.3)$ & $36.8(27.7-47.0)$ \\
\hline Being so restless that it is hard to sit still & $28.8(18.1-42.6)$ & $24.2(16.6-33.9)$ \\
\hline Becoming easily annoyed or irritable & $30.8(19.7-44.6)$ & $26.3(18.4-36.1)$ \\
\hline Feeling afraid as if something awful might happen & $46.2(33.1-59.8)$ & $41.1(31.6-51.3)$ \\
\hline Total Score ${ }^{b}$ & $40.4(27.9-54.2)$ & $35.8(26.7-46.0)$ \\
\hline
\end{tabular}

CAM-ICU = Confusion Assessment Method for ICU

GAD-7 = Generalized Anxiety Disorder-7

${ }^{a}$ Each item scored as 0 , not at all; 1 , several days; 2, more than half the days; 3, nearly every day

${ }^{\mathrm{b}}$ Total score 10 and above indicates clinically significant condition

'Scored as present/absent

${ }^{d}$ Sour Seven is scored out of 18; cutpoint of 4

The prevalence of family caregivers for critically ill patients with delirium to indicate an item score 2 or greater or to report a total score that indicates clinically significant anxiety

All values represent $\%$ with $95 \% \mathrm{Cls}$

Bold text indicates most prevalent symptoms of anxiety

delirium in critically ill patients negatively affects family caregivers and may increase the likelihood of experiencing anxiety symptoms associated with GAD, particularly worrying about too many things. Second, we found no significant difference between clinically significant symptoms of anxiety in family caregivers of critically ill patients with delirium when delirium was assessed using a clinical or the family-administered tool. This may suggest that delirium assessed by a family caregiver had no effect on caregiver anxiety.

Consistent with previous studies [31-35], anxiety symptoms were highly prevalent in family caregivers of critically ill adult patients. We found overall mean scores for anxiety symptom severity subgroups were higher than those reported from primary caregivers of hospitalbased individuals with mental illness [36], comparable to community-dwelling spouse or child caregivers for individuals with Alzheimer's [37], which a group identified at particularly high risk for poor psychological and mental health outcomes [38, 39]. Notably, 34\% of family caregivers reported mean GAD-7 scores above cutpoint for clinical significance and of these caregivers, $58 \%$ reported severe symptoms of anxiety.

Distinct characteristics of family caregivers who reported worse patterns of anxiety symptoms included being female and younger in age. Females are more likely to visit the ICU, be family caregivers, and spend more hours providing care [40-42]. Female caregivers are also more likely to not get enough sleep or regular physical activity [43], which indicates that females may be at increased risk for the harmful health effects of caregiver stress. Further, younger family caregivers compared to older family caregivers may face additional stressors such as financial burden and lifestyle interferences [44]. Younger caregivers may feel a disproportionate amount of emotional and physical strain that may exacerbate severity of anxiety symptoms. We also found that patient admitting diagnoses were varied and majority of patients were administered an analgesic together with a sedative. These results agree with what is reported in the literature; it is suggested the protective effects of caregiver male gender, increased caregiver age and less severe patient illness affects psychological functioning and coping with stress among family caregivers of the critically ill $[45,46]$. As we asked a single global demographic question on age and gender and did not query family caregiver coping capabilities, our data do not permit us to address age and gender differences related to psychological coping-a complex multidimensional construct [47] - in explaining patterns of family caregiver anxiety symptoms. However, our findings are consistent with those reported by Bolosi and colleagues [48] and are in line with the notion generally [49] that younger, female family caregivers of more severely critically ill patients are at increased risk of developing more clinically pronounced symptoms of anxiety during a patient's ICU stay.

Our results indicate that family caregivers of critically ill adults experience common symptoms of anxiety and that caregiving for a critically ill adult patient with delirium increases the likelihood of experiencing symptoms anxiety related to GAD. In the ICU, family caregivers are often present at bedside [50] and, playing a key role in their patients' overall care, are commonly engaged to support the patient through non-pharmacological delirium management interventions [51]. Family caregivers 


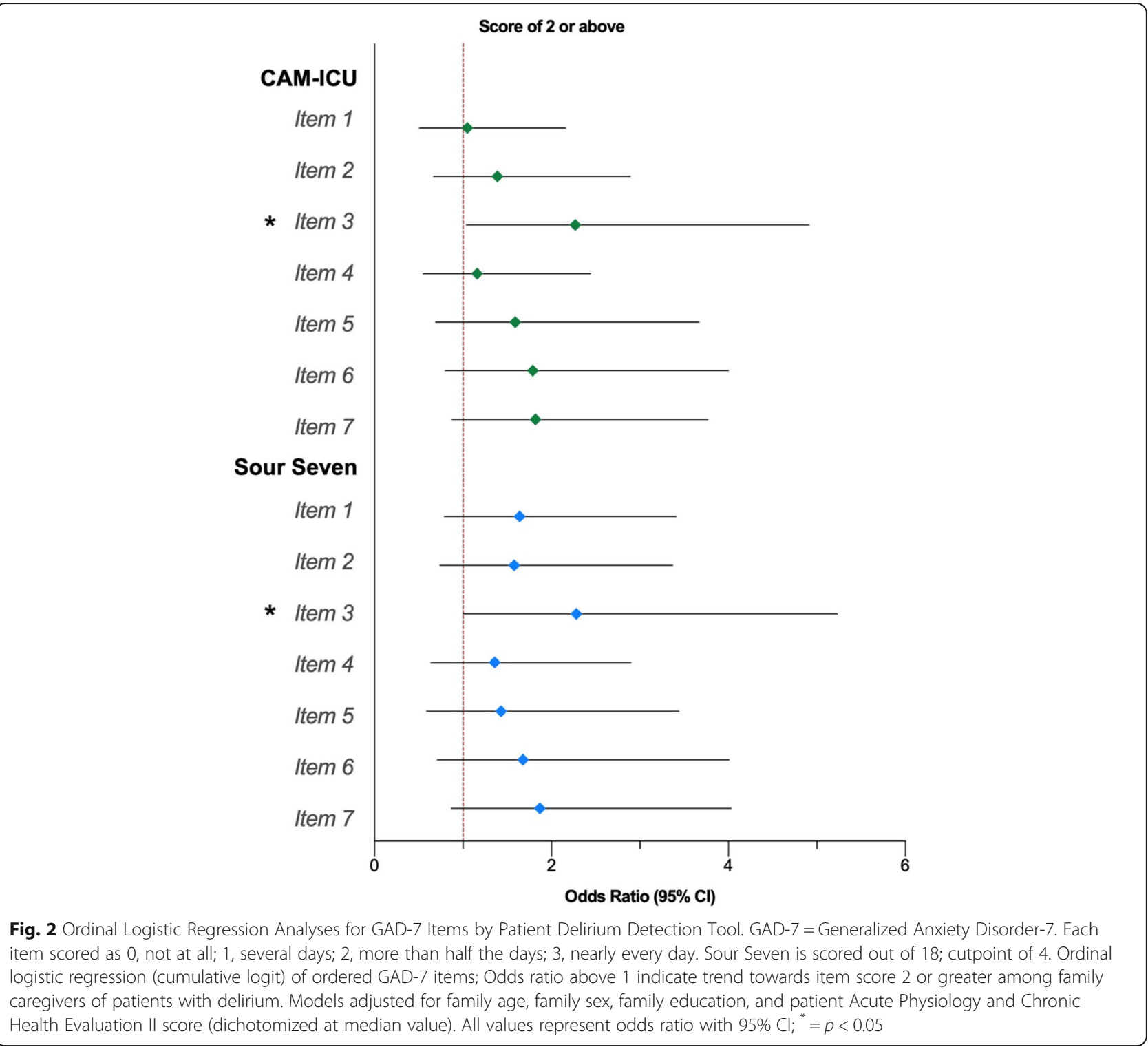

of critically ill patients with delirium frequently report the experience of seeing their loved one suffering from delirium as distressing [15]. The negative psychological sequalae experienced by family caregivers unique to their loved one's narrative of critical illness likely contributes to the pattern and severity of anxiety symptoms that they confront [52].

Several studies in various practice settings indicate that patient delirium is distressing to family caregivers [5355]. Cross-sectional studies have reported that family caregivers of cancer patients with caregiver-detected delirium were significantly more likely to meet criteria for GAD [56]. Our previous work in this cohort found that caregiver-detected delirium score was associated with severity of family caregiver anxiety symptoms (coefficient 0.2 , 95\% CI 0.1-0.4) [57]. The present findings narrow down the association of family caregiver anxiety and ICU patient delirium to a single item on the GAD-7. It is possible that the relatively small sample size resulted in insufficient power to detect significant associations with other items on the GAD-7. Further study using designs that account for temporality (e.g., cohort study) on the relationship between caregiver anxiety and patient delirium to distinguish patterns of anxiety symptoms in explaining mechanisms related to anxiety and delirium (i.e., psychopathology) including moderators (e.g., psychopathology, depression) is warranted. This can help develop effective interventions targeted to specific patterns of anxiety to improve anxiety symptoms among family caregivers of the critically ill.

Engaging and empowering family caregivers in patient care may yield potential benefits for caregiver anxiety 
Table 4 Ordinal Logistic Regression Analyses for GAD-7 Items by Patient Delirium Detection

\begin{tabular}{|c|c|c|c|c|}
\hline GAD-7 Items ${ }^{a}$ & $\begin{array}{l}\text { Clinical Assessment } \\
\text { CAM-ICU }^{\text {b }}\end{array}$ & $p$-value & $\begin{array}{l}\text { Family-Administered } \\
\text { Sour Seven }{ }^{c}\end{array}$ & $p$-value \\
\hline Feeling nervous, anxious or on edge & $1.05(0.51-2.16)$ & 0.89 & $1.64(0.79-3.41)$ & 0.19 \\
\hline Not being able to stop or control worrying & $1.39(0.67-2.89)$ & 0.38 & $1.58(0.74-3.37)$ & 0.24 \\
\hline Worrying too much about different things & $2.27(1.04-4.91)$ & 0.04 & $2.28(1.00-5.23)$ & 0.05 \\
\hline Trouble relaxing & $1.16(0.55-2.44)$ & 0.69 & $1.36(0.64-2.90)$ & 0.43 \\
\hline Being so restless that it is hard to sit still & $1.59(0.69-3.67)$ & 0.28 & $1.43(0.59-3.44)$ & 0.42 \\
\hline Becoming easily annoyed or irritable & $1.79(0.80-4.00)$ & 0.15 & $1.68(0.71-4.01)$ & 0.24 \\
\hline Feeling afraid as if something awful might happen & $1.82(0.88-3.77)$ & 0.11 & $1.87(0.87-4.03)$ & 0.11 \\
\hline
\end{tabular}

CAM-ICU = Confusion Assessment Method for ICU

GAD-7 = Generalized Anxiety Disorder-7

${ }^{a}$ Each item scored as 0 , not at all; 1 , several days; 2, more than half the days; 3, nearly every day

${ }^{b}$ Scored as present/absent

'Sour Seven is scored out of 18; cutpoint of 4

Ordinal logistic regression (cumulative logit) of ordered GAD-7 items; Odds ratio above 1 indicate trend towards item score 2 or greater among family caregivers of patients with delirium

Models adjusted for family age, family sex, family education, and patient Acute Physiology and Chronic Health Evaluation II score (dichotomized at median value)

All values represent odds ratio with $95 \% \mathrm{Cls}$

symptoms when risk factors for anxiety are incorporated in designing mental health strategies for improved psychological outcomes [58]. Highly resilient individuals are known to proactively cultivate positive adaptations [59]. Incorporating positive mental health strategies that promote for examples humanity (love, kindness) or transcendence (hope, spirituality) might allow family caregivers to adapt to the evolving demands and stress of the critical illness experience [60,61]. These strategies could also improve positive psychological coping behaviors $[62,63]$ and the symptoms of anxiety, especially in female family caregivers. We recommend future mental health interventions targeted to family caregivers' anxiety in the ICU consider both negative (e.g., anxiety) and positive (e.g., humanity, transcendence) psychological outcomes.

Our results require cautious interpretation. The crosssectional nature of data acquisition meant we were unable to detect incident family caregiver anxiety or patient delirium. Enrollment and initial assessments of patientfamily dyads occurred after ICU admission, thus no baseline data for anxiety symptoms or patient cognitive functioning were available. These results may not be generalizable to other populations given our study was conducted at a single-centre in a single-payer healthcare system; however, this tertiary care medical centre serves a catchment area of 1.8 million people. Family caregivers were not always present at bedside, making consecutive delirium and anxiety assessments over a standardized timeframe challenging. Considering family caregivers with less severe symptoms are more likely to engage in research [64], our study may have a potential selection bias for family caregivers with less severe symptoms of anxiety; therefore, the burden of anxiety might be greater than estimated. As well, family-administered delirium detection tools have lower diagnostic accuracy compared to clinical assessments of patient delirium, though their operating characteristics are fair [18] and pose a viable option when clinical assessments are not feasible [65].

\section{Conclusions}

Family caregivers of critically ill adult patients often experience clinically significant symptoms of anxiety and are significantly more likely to report frequently worrying too much about different things when their loved one develops delirium. Our findings suggest delirium in critically ill patients negatively affects family caregivers to increase the likelihood of experiencing anxiety symptoms associated with GAD. Longitudinal studies of the patterns of anxiety in caregivers of critically ill patients with delirium is necessary to develop targeted treatments and interventions to improve anxiety symptoms.

\section{Supplementary Information}

The online version contains supplementary material available at https://doi. org/10.1186/s12913-021-07218-1.

Additional file 1.

Acknowledgements

Not applicable.

Availability of the data an materials

The data that support the findings of this study are available from Alberta Health Services but restrictions apply to the availability of these data, which were used under license for the current study, and so are not publicly available. Data are however available from the authors upon reasonable request and with permission of the University of Calgary Conjoint Health Research Ethics Board and Alberta Health Services. 


\section{Authors' contributions}

All those designated as authors (TGP, KDK, BKR, HTS, KMF, SJM) have met all ICMJE criteria for authorship: Substantial contributions to the conception or design of the work; or the acquisition, analysis, or interpretation of data for the work; AND Drafting the work or revising it critically for important intellectual content; AND Final approval of the version to be published; AND Agreement to be accountable for all aspects of the work in ensuring that questions related to the accuracy or integrity of any part of the work are appropriately investigated and resolved. SJM and KMF had full access to all of the data in the study and take full responsibility for the integrity of the data and the accuracy of the data analysis. Concept and design: TGP, KDK, KMF, SJM. Acquisition, analysis, or interpretation of data: TGP, KDK, BKR, KMF, SJM. Drafting of the manuscript: TGP, KMF, SJM. Critical revision of the manuscript: TGP, KDK, BKR, HTS, KMF, SJM. Statistical analysis: SJM. Administrative technical, or material support: HTS, KMF.

\section{Funding}

Supported, in part, by grants from the Medical Services Incorporated Foundation, Canadian Institutes of Health Research, and Alberta Health Services (to Dr. Fiest). This research is funded by Canadian Frailty Network (Technology Evaluation in the Elderly Network), which is supported by the Government of Canada through the Networks of Centres of Excellence program (to Dr. Fiest). Dr. Moss was supported by a CIHR Doctoral Research Award.

\section{Declarations}

\section{Ethics approval and consent to participate}

Informed consent was sought for all participants of the study. All protocols were carried out in accordance with relevant guidelines and regulations approved by the Conjoint Health Research Ethics Board at the University of Calgary (REB 16-2060) and Alberta Health Services. The study is reported according to Strengthening the Reporting of Observational Studies in Epidemiology (STROBE) guidelines.

\section{Consent for publication}

Not applicable.

\section{Competing interests}

The authors have no competing interests relevant to this work.

\section{Author details}

'Department of Critical Care Medicine, Cumming School of Medicine, University of Calgary, Calgary, AB T2N 1N4, Canada. ${ }^{2}$ Department of Critical Care Medicine, Cumming School of Medicine, University of Calgary, Calgary, AB T2N 1N4, Canada. ${ }^{3}$ Departments of Community Health Sciences and Critical Care Medicine, Cumming School of Medicine, University of Calgary, Calgary, AB T2N 1N4, Canada. ${ }^{4}$ Departments of Community Health Sciences and Critical Care Medicine, Cumming School of Medicine, University of Calgary, Calgary, AB T2N 1N4, Canada. ${ }^{5}$ Departments of Critical Care Medicine, Community Health Sciences \& Psychiatry, Cumming School of Medicine, University of Calgary, Calgary, AB T2N 1N4, Canada. ${ }^{6}$ Departments of Community Health Sciences and Critical Care Medicine, Cumming School of Medicine, University of Calgary, Calgary, AB T2N 1N4, Canada.

\section{Received: 17 January 2021 Accepted: 22 October 2021}

Published online: 05 November 2021

\section{References}

1. Nelson JE, Cox CE, Hope AA, Carson SS. Chronic critical illness. Am J Respir Crit Care Med. 2010;182(4):446-54. https://doi.org/10.1164/rccm.201002-021 OCl.

2. Finfer S, Vincent JL. Critical care--an all-encompassing specialty. N Engl J Med. 2013;369(7):669-70. https://doi.org/10.1056/NEJMe1304035.

3. Halpern NA, Pastores SM. Critical care medicine in the United States 20002005: an analysis of bed numbers, occupancy rates, payer mix, and costs. Crit Care Med. 2010;38(1):65-71. https://doi.org/10.1097/CCM.0b013e3181 b090d0.

4. Hosie A, Davidson PM, Agar M, Sanderson CR, Phillips J. Delirium prevalence, incidence, and implications for screening in specialist palliative care inpatient settings: a systematic review. Palliat Med. 2013;27(6):486-98. https://doi.org/10.1177/0269216312457214.

5. Diwell RA, Davis DH, Vickerstaff V, Sampson EL. Key components of the delirium syndrome and mortality: greater impact of acute change and disorganised thinking in a prospective cohort study. BMC Geriatr. 2018;18(1): 24. https://doi.org/10.1186/s12877-018-0719-1.

6. Leslie DL, Inouye SK. The importance of delirium: economic and societal costs. J Am Geriatr Soc. 2011;59(Suppl 2):S241-3. https://doi.org/10.1111/j.1 532-5415.2011.03671.x.

7. Morandi A, Jackson JC, Ely EW. Delirium in the intensive care unit. Int Rev Psychiatry. 2009;21(1):43-58. https://doi.org/10.1080/09540260802 675296.

8. Rizzo JA, Bogardus ST Jr, Leo-Summers L, Williams CS, Acampora D, Inouye SK. Multicomponent targeted intervention to prevent delirium in hospitalized older patients: what is the economic value? Med Care. 2001; 39(7):740-52. https://doi.org/10.1097/00005650-200107000-00010.

9. Brummel NE, Girard TD. Preventing delirium in the intensive care unit. Crit Care Clin. 2013;29(1):51-65. https://doi.org/10.1016/j.ccc.2012.10.007.

10. Tate JA, Devito Dabbs A, Hoffman LA, Milbrandt E, Happ MB. Anxiety and agitation in mechanically ventilated patients. Qual Health Res. 2012;22(2): 157-73. https://doi.org/10.1177/1049732311421616.

11. Burns KEA, Misak C, Herridge M, Meade MO, Oczkowski S. Patient, family Partnership Committee of the Canadian Critical Care Trials G: patient and family engagement in the ICU. Untapped opportunities and Underrecognized challenges. Am J Respir Crit Care Med. 2018;198(3):310-9. https://doi.org/10.1164/rccm.201710-2032Cl.

12. O'Malley G, Leonard M, Meagher D, O'Keeffe ST. The delirium experience: a review. J Psychosom Res. 2008;65(3):223-8. https://doi.org/10.1016/j. jpsychores.2008.05.017.

13. Leonard M, Agar M, Mason C, Lawlor P. Delirium issues in palliative care settings. J Psychosom Res. 2008;65(3):289-98. https://doi.org/10.1016/j. jpsychores.2008.05.018.

14. Day J, Higgins I. Adult family member experiences during an older loved one's delirium: a narrative literature review. J Clin Nurs. 2015;24(11-12): 1447-56. https://doi.org/10.1111/jocn.12771.

15. Partridge JS, Martin FC, Harari D, Dhesi JK. The delirium experience: what is the effect on patients, relatives and staff and what can be done to modify this? Int J Geriatr Psychiatry. 2013;28(8):804-12. https://doi.org/10.1002/gps.3 900.

16. Finucane AM, Lugton J, Kennedy C, Spiller JA. The experiences of caregivers of patients with delirium, and their role in its management in palliative care settings: an integrative literature review. Psychooncology. 2017;26(3):291300. https://doi.org/10.1002/pon.4140.

17. Krewulak KD, Sept BG, Stelfox HT, Ely EW, Davidson JE, Ismail Z, et al. Feasibility and acceptability of family administration of delirium detection tools in the intensive care unit: a patient-oriented pilot study. CMAJ Open. 2019;7(2):E294-9. https://doi.org/10.9778/cmajo.20180123.

18. Fiest KM, Krewulak KD, Ely EW, Davidson JE, Ismail Z, Sept BG, et al. Partnering with family members to detect delirium in critically ill patients. Crit Care Med. 2020;48(7):954-61. https://doi.org/10.1097/CCM. 0000000000004367.

19. Ely JW, Osheroff JA, Chambliss ML, Ebell MH, Rosenbaum ME. Answering physicians' clinical questions: obstacles and potential solutions. J Am Med Inform Assoc. 2005;12(2):217-24. https://doi.org/10.1197/jamia.M1608.

20. Stevens RD, Nyquist PA. Types of brain dysfunction in critical illness. Neurol Clin. 2008;26(2):469-86, ix. https://doi.org/10.1016/j.ncl.2008.02.004.

21. Tonelli MR, Misak CJ. Compromised autonomy and the seriously ill patient. Chest. 2010;137(4):926-31. https://doi.org/10.1378/chest.09-1574.

22. Ely EW, Inouye SK, Bernard GR, Gordon S, Francis J, May L, et al. Delirium in mechanically ventilated patients: validity and reliability of the confusion assessment method for the intensive care unit (CAM-ICU). JAMA. 2001; 286(21):2703-10. https://doi.org/10.1001/jama.286.21.2703.

23. Brundin-Mather R, Soo A, Zuege DJ, Niven DJ, Fiest K, Doig CJ, et al. Secondary EMR data for quality improvement and research: a comparison of manual and electronic data collection from an integrated critical care electronic medical record system. J Crit Care. 2018;47:295-301. https://doi. org/10.1016/j.jcrc.2018.07.021.

24. Shulman RW, Kalra S, Jiang JZ. Validation of the sour seven questionnaire for screening delirium in hospitalized seniors by informal caregivers and untrained nurses. BMC Geriatr. 2016;16(1):44. https://doi.org/10.1186/s12877016-0217-2. 
25. Spitzer RL, Kroenke K, Williams JB, Lowe B. A brief measure for assessing generalized anxiety disorder: the GAD-7. Arch Intern Med. 2006;166(10): 1092-7. https://doi.org/10.1001/archinte.166.10.1092.

26. Lowe B, Spitzer RL, Williams JB, Mussell M, Schellberg D, Kroenke K. Depression, anxiety and somatization in primary care: syndrome overlap and functional impairment. Gen Hosp Psychiatry. 2008;30(3):191-9. https:// doi.org/10.1016/j.genhosppsych.2008.01.001

27. Seo JG, Park SP. Validation of the generalized anxiety Disorder-7 (GAD-7) and GAD-2 in patients with migraine. J Headache Pain. 2015;16(1):97. https://doi.org/10.1186/s10194-015-0583-8.

28. Chang C: Response feature analysis of longitudinal data in medical research. In: 2000; 2000.

29. Fong TG, Tulebaev SR, Inouye SK. Delirium in elderly adults: diagnosis, prevention and treatment. Nat Rev Neurol. 2009;5(4):210-20. https://doi. org/10.1038/nrneurol.2009.24

30. Trzepacz PT, Franco JG, Meagher DJ, Lee Y, Kim JL, Kishi Y, et al. Delirium phenotype by age and sex in a pooled data set of adult patients. J Neuropsychiatry Clin Neurosci. 2018;30(4):294-301. https://doi.org/10.1176/a ppi.neuropsych.18020024.

31. Azoulay E, Pochard F. Communication with family members of patients dying in the intensive care unit. Curr Opin Crit Care. 2003;9(6):545-50. https://doi.org/10.1097/00075198-200312000-00014.

32. Pochard F, Darmon M, Fassier T, Bollaert PE, Cheval C, Coloigner M, et al. Symptoms of anxiety and depression in family members of intensive care unit patients before discharge or death. A prospective multicenter study. J Crit Care. 2005;20(1):90-6. https://doi.org/10.1016/j.jcrc.2004.11.004.

33. Jones C, Skirrow P, Griffiths RD, Humphris G, Ingleby S, Eddleston J, et al. Post-traumatic stress disorder-related symptoms in relatives of patients following intensive care. Intensive Care Med. 2004;30(3):456-60. https://doi. org/10.1007/s00134-003-2149-5.

34. Curtis JR, Treece PD, Nielsen EL, Gold J, Ciechanowski PS, Shannon SE, et al. Randomized trial of communication facilitators to reduce family distress and intensity of end-of-life care. Am J Respir Crit Care Med. 2016;193(2):154-62. https://doi.org/10.1164/rccm.201505-09000C.

35. Celik S, Genc G, Kinetli Y, Asiliogli M, Sari M, Madenoglu Kivanc M. Sleep problems, anxiety, depression and fatigue on family members of adult intensive care unit patients. Int J Nurs Pract. 2016;22(5):512-22. https://doi. org/10.1111/ijn.12451.

36. Jeyagurunathan A, Sagayadevan V, Abdin E, Zhang Y, Chang S, Shafie S, et al. Psychological status and quality of life among primary caregivers of individuals with mental illness: a hospital based study. Health Qual Life Outcomes. 2017;15(1):106. https://doi.org/10.1186/s12955-017-0676-y.

37. Parker Oliver D, Washington K, Smith J, Uraizee A, Demiris G. The prevalence and risks for depression and anxiety in hospice caregivers. J Palliat Med. 2017;20(4):366-71. https://doi.org/10.1089/jpm.2016.0372.

38. Russo J, Vitaliano PP, Brewer DD, Katon W, Becker J. Psychiatric disorders in spouse caregivers of care recipients with Alzheimer's disease and matched controls: a diathesis-stress model of psychopathology. J Abnorm Psychol. 1995;104(1):197-204. https://doi.org/10.1037/0021-843X.104.1.197.

39. Dura JR, Stukenberg KW, Kiecolt-Glaser JK. Anxiety and depressive disorders in adult children caring for demented parents. Psychol Aging. 1991;6(3): 467-73. https://doi.org/10.1037/0882-7974.6.3.467.

40. Alsharari AF. The needs of family members of patients admitted to the intensive care unit. Patient Prefer Adherence. 2019;13:465-73. https://doi. org/10.2147/PPA.S197769.

41. Maxwell KE, Stuenkel D, Saylor C. Needs of family members of critically ill patients: a comparison of nurse and family perceptions. Heart Lung. 2007; 36(5):367-76. https://doi.org/10.1016/j.hrtlng.2007.02.005.

42. Hinkle $J$, Fitzpatrick $E$. Needs of American relatives of intensive care patients: perceptions of relatives, physicians and nurses. Intensive Crit Care Nurs. 2011;27(4):218-25. https://doi.org/10.1016/j.iccn.2011.04.003.

43. Pinquart $M$, Sorensen $S$. Differences between caregivers and noncaregivers in psychological health and physical health: a meta-analysis. Psychol Aging 2003;18(2):250-67. https://doi.org/10.1037/0882-7974.18.2.250

44. van Beusekom I, Bakhshi-Raiez F, de Keizer NF, Dongelmans DA, van der Schaaf M. Reported burden on informal caregivers of ICU survivors: a literature review. Crit Care. 2016;20(1):16. https://doi.org/10.1186/s13054-016-1185-9.

45. Oliveira HSB, Fumis RRL. Sex and spouse conditions influence symptoms of anxiety, depression, and posttraumatic stress disorder in both patients admitted to intensive care units and their spouses. Rev Bras Ter Intensiva. 2018;30(1):35-41. https://doi.org/10.5935/0103-507X.20180004.
46. Kose I, Zincircioglu C, Ozturk YK, Cakmak M, Guldogan EA, Demir HF, et al. Factors affecting anxiety and depression symptoms in relatives of intensive care unit patients. J Intensive Care Med. 2016;31(9):611-7. https://doi.org/1 $0.1177 / 0885066615595791$.

47. Endler NS, Parker JD. Multidimensional assessment of coping: a critical evaluation. J Pers Soc Psychol. 1990;58(5):844-54. https://doi.org/10.1037/ 0022-3514.58.5.844.

48. Bolosi M, Peritogiannis V, Tzimas P, Margaritis A, Milios K, Rizos DV. Depressive and anxiety symptoms in relatives of intensive care unit patients and the perceived need for support. J Neurosci Rural Pract. 2018;9(4):522-8. https://doi.org/10.4103/jnrp.jnrp_112_18.

49. Johnson CC, Suchyta MR, Darowski ES, Collar EM, Kiehl AL, Van J, et al. Psychological sequelae in family caregivers of critically III intensive care unit patients. A systematic review. Ann Am Thorac Soc. 2019;16(7):894-909. https://doi.org/10.1513/AnnalsATS.201808-540SR

50. Jackson JC, Mitchell N, Hopkins RO. Cognitive functioning, mental health, and quality of life in ICU survivors: an overview. Crit Care Clin. 2009;25(3): 615-28, x. https://doi.org/10.1016/j.ccc.2009.04.005.

51. Bezanson K, Rogers S: Delirium and Acute Anxiety. In., edn.; 2019: 46-52.

52. Williams ST, Dhesi JK, Partridge JSL. Distress in delirium: causes, assessment and management. Eur Geriatr Med. 2020;11(1):63-70. https://doi.org/10.1 007/s41999-019-00276-z.

53. Morita T, Akechi T, Ikenaga M, Inoue $S$, Kohara H, Matsubara T, et al. Terminal delirium: recommendations from bereaved families' experiences. J Pain Symptom Manag. 2007;34(6):579-89. https://doi.org/10.1016/j.jpainsymman.2007.01.012.

54. Grover $\mathrm{S}$, Shah R. Delirium-related distress in caregivers: a study from a tertiary care Centre in India. Perspect Psychiatr Care. 2013;49(1):21-9. https:// doi.org/10.1111/j.1744-6163.2012.00335.x.

55. Bruera E, Bush SH, Willey J, Paraskevopoulos T, Li Z, Palmer JL, et al. Impact of delirium and recall on the level of distress in patients with advanced cancer and their family caregivers. Cancer. 2009;115(9):2004-12. https://doi. org/10.1002/cncr.24215.

56. Buss MK, Vanderwerker LC, Inouye SK, Zhang B, Block SD, Prigerson HG. Associations between caregiver-perceived delirium in patients with cancer and generalized anxiety in their caregivers. J Palliat Med. 2007;10(5):108392. https://doi.org/10.1089/jpm.2006.0253.

57. Rosgen BK, Krewulak KD, Davidson JE, Ely EW, Stelfox HT, Fiest KM. Associations between caregiver-detected delirium and symptoms of depression and anxiety in family caregivers of critically ill patients: a crosssectional study. BMC Psychiatry. 2021;21(1):187. https://doi.org/10.1186/s12 888-021-03200-7.

58. Sottile PD, Lynch Y, Mealer M, Moss M. Association between resilience and family member psychologic symptoms in critical illness. Crit Care Med. 2016;44(8):e721-7. https://doi.org/10.1097/CCM.0000000000001673.

59. Anderson EW, White KM. "This is what family does": the family experience of caring for serious illness. Am J Hosp Palliat Care. 2018;35(2):348-54. https:// doi.org/10.1177/1049909117709251.

60. Block J, Kremen AM. IQ and ego-resiliency: conceptual and empirical connections and separateness. J Pers Soc Psychol. 1996;70(2):349-61. https://doi.org/10.1037/0022-3514.70.2.349.

61. Lazarus RS. From psychological stress to the emotions: a history of changing outlooks. Annu Rev Psychol. 1993;44(1):1-21. https://doi.org/1 0.1146/annurev.ps.44.020193.000245.

62. Kumpfer KL, Bluth B. Parent/child transactional processes predictive of resilience or vulnerability to "substance abuse disorders". Subst Use Misuse. 2004;39(5):671-98. https://doi.org/10.1081/JA-120034011.

63. Kumpfer KL, Summerhays JF. Prevention approaches to enhance resilience among high-risk youth: comments on the papers of Dishion \& Connell and Greenberg. Ann N Y Acad Sci. 2006;1094(1):151-63. https://doi.org/10.1196/a nnals.1376.014.

64. Barello S, Castiglioni C, Bonanomi A, Graffigna G. The caregiving health engagement scale (CHE-s): development and initial validation of a new questionnaire for measuring family caregiver engagement in healthcare. BMC Public Health. 2019;19(1):1562. https://doi.org/10.1186/s12889-019-7743-8.

65. Penoyer DA. Nurse staffing and patient outcomes in critical care: a concise review. Crit Care Med. 2010;38(7):1521-8; quiz 1529. https://doi.org/10.1097/ cCM.0b013e3181e47888.

\section{Publisher's Note}

Springer Nature remains neutral with regard to jurisdictional claims in published maps and institutional affiliations. 